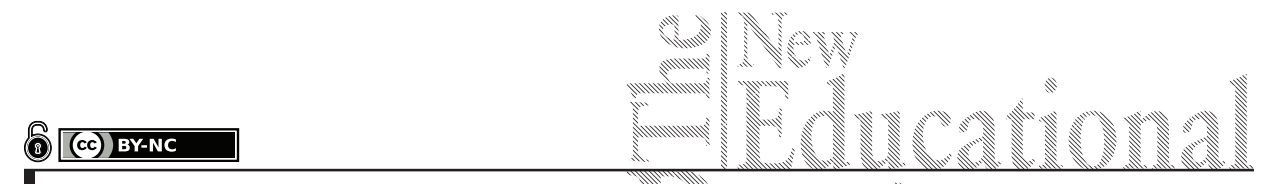

Katarzyna Kacka, Bartłomiej Michalak, Joanna Piechowiak-Lamparska

Poland

\title{
Impact of Scholarly Publications and the Selected Socio-Demographic Factors
}

DOI: $10.15804 /$ tner.2018.52.2.13

\begin{abstract}
In a dynamically developing scientific environment, there is a tendency toward creating mechanisms that objectively evaluate the output of individual scientific units. Selected indicators can be applied, inter alia, to work out specific criteria for awarding funds for scientific research activities. One of the most important indicators used is the impact of researchers' publications, which today determines the overall outcome of the evaluation of a research unit. The key question in this context is whether any socio-demographic factors are correlated with the impact of the scholarship work of individual researchers and, if yes, what those indicators are, specifically. The purpose of this study was to determine the existence and, if confirmed, the nature of correlation between the impact of researchers' publications and selected socio-demographic factors such as: age, gender and family status. The study sample included all the academic employees of the Faculty of Political Sciences and International Studies, Nicolaus Copernicus University, in Torun (Poland). The results demonstrated that the socio-demographic factors considered showed little correlation with publications' impactfulness as measured in the Polish evaluation system of research units.
\end{abstract}

Keywords: evaluation of scientific research, publication impact, socio-demographic variables, social sciences, the humanities 


\section{Introduction}

The issue of the effectiveness of tasks carried out at work is one of the most important topics in the field of HR research, also in the domain of science (Carayol \& Matt, 2006). Therefore, the question arises which factors make scholars work better, more efficiently and effectively. At present, quantitative and qualitative assessment is carried out also for universities that must provide reports on their scientific and educational activities. Evaluation of scientific and research activity is, however, very difficult; should one take into account the number of Nobel Prize winners employed, the quantity of prestigious publications or the monetary value of registered patents? Maybe all of the above and some additional elements should be combined into a complex multifactor calculation model? One undisputed fact, however, remains - that the basic channel of communication between scientists, but also between the world of science and its social and economic environment, are scholarly publications.

So far, no research on the impactfulness of publications taking into account a broad range of sociodemographic factors has been conducted in Poland. Often in the atmosphere of reluctance, protests and dissent, the scientific community was until recently engaged in the laborious exercise of determining what is a prestigious publication. Now in the case of Polish science there is no need for further discussions - this problem has been solved institutionally by the Ministry of Science and Higher Education (MSHE). In a broad definition, an employee with high impactfulness of publications is one that publishes a lot and in prestigious journals. University management should, thus, be interested in which factors are correlated with the high impact of a researcher's scholarly work, which in turn is profitable for the university (Jeran, Kącka \& Piechowiak-Lamparska, 2017). Every employee, after all, can be described in terms of family situation, age and gender. It is thus worth investigating whether any and - if yes - which sociodemographic factors are correlated with the impactfulness of publications. What makes the presented research results unique is the addition of family status to the range of factors considered. The discussion of the impact of gender and age can be found in the work of other researchers, but such a detailed and comprehensive approach as the one presented herein is very rare.

Similar studies have been carried out at the University of Helsinki, Finland, where Puuska (2010) stated clearly that the scientific productivity of university employees is sensitive to some sociodemographic variables only. After examining data of 12,400 Norwegian scientists, Rørstad \& Aksnes (2015) showed that scientific productivity and impactfulness is more significantly influenced by one's 
position than gender and age. However, these deviations at the individual level must depend on factors other than those taken into account by these authors. It is thus reasonable to suggest investigating other sociodemographic factors as possible co-determinants (e.g., family status), instead of agreeing that this issue must remain elusive and must be attributed solely to undefinable "inspiration".

The study is based on a detailed analysis of the structure of scholarship work and the socio-demographic variables of the complete population of employees of the Faculty of Political Sciences and International Studies (FPSIS), Nicolaus Copernicus University (NCU) in Torun (Poland). Due to a relatively small sample, the results of the analysis cannot be extrapolated onto the entire scientific community in Poland and the authors of the paper are well aware of the fact. Nevertheless, the sample size allows for the research to be considered as a case $s t u d y$, which may be an interesting contribution to any research focused on scholars and research units at a national level, as well as to studies analyzing particular domains of science or disciplines. The basic research question put forward in this paper is: Are socio-demographic factors correlated with the impact of scholarship work of individual researchers? The answer is particularly interesting since the present study is a pioneering one - so far, no results of multi-variate analyses focused on links between a scholar's publications' impact and socio-demographic variables have been published. One of the barriers in conducting such research is the difficulty of the acquisition and aggregation of sensitive data.

\section{Research Methodology}

\subsection{Materials and variables}

The following data sets were used to perform the presented analysis:

1. Scientific publications of the staff of FPSIS for the years 2013-2016 (parametric evaluation period).

2. Information on the key socio-demographic traits of the researchers employed by FPSIS: age, sex, civil status (married, cohabitating, single), family status (dependent minor children under direct care of an employee, no such dependent children).

3. Specific point scores obtained by individual employees were calculated on the basis of publication data from the Expertus system (Bibliography of publications of employees and doctoral students at NCU in Toruń). The publications were catalogued and aggregated according to the division provided for in the MSHE Regulation (2016). Next, they were assigned 
parametric points in accordance with the same MSHE Regulation (2016) and the Catalogue of Scientific Periodicals with a full history of their position in the published catalogues of scientific periodicals in the years 2013-2016 and corresponding points to be awarded (2017). In the analysis, the total points earned by the employees according to the MSHE scoring system were split into two categories: 1. Relevant (impactful) points (points for publications that were taken into account in the final parametric evaluation and were above the cut-off line (177); and 2. Irrelevant (lost) points (points for publications that were not considered in the parametric evaluation of the unit (below cut-off point).

\subsection{Objectives of the study}

The purpose of the study was to determine the existence of (and if existing, the nature of) a correlation between selected socio-demographic variables (independent variables) and the publication impact of the researchers employed at the FPSIS as measured by relevant points awarded by the MSHE for scientific publications of the unit's employees depending on their ranking as part of the process of parametric evaluation of scientific and research units in Poland (dependent variable).

The following specific research questions were posed:

Q1. Is there a statistically significant relationship between employee age and impact achieved by their publications in terms of the final number of impactful points awarded in the evaluation, and if so, is it positively or negatively correlated?

Q2. Do men and women differ in the impact achieved by their publications in terms of relevant points obtained in the evaluation process?

Q3. Does the civil and family situation of a worker correlate with the impact achieved by their publications in terms of impactful (relevant) points awarded in the evaluation?

These questions led us to the suggested interlinked answers (research hypotheses):

H1. There is a negative and statistically significant relationship between employee age and the impact achieved by their publications in terms of relevant (impactful) points obtained in the evaluation process.

Researchers' age is one of the basic factors analyzed in studies addressing the issue of scientific productivity and impactfulness (cf., e.g., Costas, van Leeuwen \& Bordons, 2010; Abramo, D’Angelo \& Di Costa, 2011; Rørstad \& Aksnes, 2015; Abramo, D'Angelo \& Murgia, 2015). The results obtained definitely show that it is not the main determinant of increased productivity and impact of publications, although indeed the older the employee the less they publish. The analyses carried 
out by Cole (1979) at the end of the 1970s show that, in fact, scholarly productivity of researchers is noticeably decreasing with age, but this fact was attributed by Cole primarily to low attractiveness of reward systems in place in the scientific community, and not age as expressed purely in numbers. Studies by Cronin \& Meho (2007) confirm these results. However, these two authors also draw attention to the fact that productivity and impact in terms of publications decrease with age, because creativity of well-established academics can be and is at that stage expressed in various alternative ways, e.g., through reviews or efforts aimed at popularization of one's research results, which significantly reduces the number of publications.

Taking into account the conclusions from the above studies, we also assumed that among the academic employees of the FPSIS, age is not a factor significantly influencing the publication impactfulness scores. Of course we are aware that the younger (and less tenured) the employee, the more they should want to demonstrate their scientific abilities and scholarship. It would, thus, be logical to expect that younger employees would exhibit greater scientific activity than older researchers simply for pragmatic reasons related to their professional situation and desire for prestige. They would therefore want to demonstrate their suitability and usefulness for the organization that employs them, to expand their scholarly output needed for professional advancement, increase their personal prestige, and consequently gain access to financially more lucrative positions within the unit.

H2. Gender is not correlated with the number of relevant (impactful) points scored by an employee.

Usually, gender is a differentiating factor, and results of analyses show different outcomes for men and women. The practice of distinguishing this particular socio-demographic variable as a relevant one has a very long and well-documented tradition in research. In some fields of research, gender is even a key predictor. Such is the case, e.g., in the study of electoral behavior, where, regardless of the current socio-political context, there is a continuing trend of greater voting activity of men than women.

So far, there have been many studies focusing on the relationship between gender and productivity in terms of publications. The conclusions from these studies have been evolving over the years, and the newest indicate that gender is not a variable significantly influencing scientific productivity and impact of one's scholarly publication (in the early 1990s, research conducted in the Netherlands at the University of Leiden showed that women can be well organized and publish prolifically, Noordenbos, 1992). Moreover, Kelchtermans \& Veugelers (2013) have 
shown that in biomedical sciences women are more productive over the long-term. Kretschmer \& Kretschmer (2013) refuted four misconceptions about women in science and at the same time stated that the widespread popularity of these myths may be the reason for the under-representation of women at the highest levels of hierarchy in the world of academia.

We assume that also among the FPSIS employees gender is not a factor differentiating the impact and productivity of a researcher's publications. Nevertheless, we decided that, despite many studies in this area, it is still worth analysing the widest possible range of sociodemographic factors in our work, gender included.

H3. Absence of family responsibilities in the form of a spouse (or steady partner) and minor children remaining directly under a researcher's care promotes a larger number of relevant (impactful) points obtained.

From the conducted review of literature on scientific productivity and impact as measured by publications, it became clear that analyzing the correlation between the impactfulness of a researcher's publications and their family obligations is a unique and innovative approach. No one has conducted similar analyses thus far.

We hypothesized that lack of family responsibilities and obligations such as those arising from marriage or partnership and having no children under direct care (i.e., not only sharing in the costs of a child's maintenance, but living together in one household with the child, which gives rise to additional time-consuming responsibilities) should facilitate obtaining more relevant (impactful) points for one's publication. We are aware that in practice familial relationships and related obligations of science employees (as in other professions) go far beyond matrimonial/partnership and parental relationships. Without knowing the exact personal situation of an individual, any inference based solely on their marital/relationship status and their number of children can only be of a very simplistic nature.

\subsection{Characteristics of the data set}

The collected data set consists of 61 units of enquiry (61 academic employees of the FPSIS), and the analyzed data are mostly quantitative variables. All dependent variables referring to employee publication impact (as expressed by the number of relevant points obtained during the unit evaluation process) and the independent variable "age" are ratio variables. Only the variables of gender, civil status, and family situation are nominal, the first of which is of dichotomous nature. This gave us the opportunity to analyze and test the statistical significance of the collected data using tools such as regression analysis and correlation coefficients (R-Pearson and Spearman's rank correlation coefficient). The analyzed dataset is not a repre- 
sentative sample, but can be treated as an independent and discrete population, thus giving the authors an opportunity to treat their research as a case study.

Table 1. Socio-demographic characteristics of the analyzed population

\begin{tabular}{lcc}
\hline \multicolumn{1}{c}{ Variables } & N & $\%$ \\
\hline Gender: & 21 & \\
Women & 40 & 34.43 \\
Men & & 65.57 \\
\hline Age: & 10 & \\
Under 35 & 16 & 16.39 \\
$36-40$ & 10 & 26.23 \\
$41-45$ & 7 & 16.39 \\
$46-50$ & 9 & 11.48 \\
$51-60$ & 9 & 14.75 \\
Over 60 & & 14.75 \\
\hline Civil status and family situation: & 52 & \\
In a steady relationship (marriage or cohabitation) & & 85.25 \\
At least one dependent minor child under their direct & 29 & \\
care & 61 & 100 \\
\hline Total & & \\
\hline
\end{tabular}

Source: Own analysis of data records on FPSIS employees.

\section{Research Results}

The main purpose of the study was to verify the hypotheses posited as possible answers to the research questions formulated.

H1. There is a negative and statistically significant relationship between employees' ages and the impact achieved by their publications in terms of relevant (impactful) points obtained in the evaluation process.

In this case, the independent variable was employee age, and the dependent variable analyzed were the point scores (for "total" and "impactful (relevant)" points) awarded by the MSHE for each employee publication depending on its rank. Among all the regression models tested with the use of the curve estimation function in the SPSS software (Statistical Package for the Social Sciences), the best-fit and most statistically significant $(\mathrm{p}<0.05)$ models turned out to be linear regression (for the relevant (impactful) points obtained variable) and logistic regression (for the total points obtained variable). However, their coefficient of 
determination is still negligible $(\mathrm{R}$ Square $=0.082)$ and does not explain even $10 \%$ of the variance.

This does not mean, however, that researcher age does not matter. The Pearson $\mathrm{R}$ correlation coefficient, assuming the above significance level, was recorded at $\mathrm{R}=-0.282$ for the first of the dependent variables and -0.0286 for the second. This indicates that there is a negative, if weak, correlation between age and number of relevant (impactful) points obtained by an FPSIS employee. If one additionally analyzes the data broken down into the two categories resulting from recoding the ratio variable "age" into a dichotomous variable "employees under 40 years of age/over 40 years of age," a clearer relationship between these categories emerges.

Table 2. Analysis of correlation between age of FPSIS employees

(criterion of under/over 40 years of age) and the number of relevant (impactful) points obtained for publications

\begin{tabular}{|c|c|c|c|c|}
\hline \multicolumn{5}{|c|}{ Report } \\
\hline & er 40 years of age & $\begin{array}{c}\text { Points by the } \\
\text { MSHE }\end{array}$ & $\begin{array}{l}\text { Relevant (im- } \\
\text { pactful) points }\end{array}$ & $\begin{array}{c}\text { Irrelevant (lost) } \\
\text { points }\end{array}$ \\
\hline \multirow[t]{5}{*}{ No } & Sum & 3701.9 & 1258.5 & 2275.4 \\
\hline & Median & 88.237 & 26.000 & 51.667 \\
\hline & Mean & 105.769 & 35.957 & 65.012 \\
\hline & Std. Deviation & 81.3579 & 35.8577 & 53.1395 \\
\hline & $\mathrm{N}$ & 35 & 35 & 35 \\
\hline \multirow[t]{5}{*}{ Yes } & Sum & 3037.4 & 1294.5 & 1526.9 \\
\hline & Median & 107.375 & 39.000 & 47.500 \\
\hline & Mean & 116.824 & 49.788 & 58.728 \\
\hline & Std. Deviation & 73.1951 & 41.0580 & 41.6347 \\
\hline & $\mathrm{N}$ & 26 & 26 & 26 \\
\hline \multirow[t]{5}{*}{ Total } & Sum & 6739.3 & 2553.0 & 3802.3 \\
\hline & Median & 98.667 & 36.333 & 49.237 \\
\hline & Mean & 110.481 & 41.852 & 62.333 \\
\hline & Std. Deviation & 77.5468 & 38.4522 & 48.2933 \\
\hline & $\mathrm{N}$ & 61 & 61 & 61 \\
\hline
\end{tabular}

Source: Own analysis.

Employees up to the age of 40 (inclusive), as shown in Table 2, demonstrated on average a higher number of total points obtained, a higher number of relevant (impactful) points obtained, and a lower number of irrelevant (lost) points. The differences are marked - the median in the first two cases is higher by more than a dozen points. Interestingly, the "young" researchers scored more points in total 
for their publications (1294.5) and recorded fewer irrelevant (lost) points (1526.9) than the group of "older" academics (1258.5 and 2275.4 points respectively), despite the fact that the population of the former was overall smaller.

Table 3. Analysis of correlation between age of FPSIS employees (age brackets) and the number of relevant (impactful) points obtained for publications

\begin{tabular}{|c|c|c|c|c|}
\hline \multicolumn{5}{|c|}{ Report } \\
\hline \multicolumn{2}{|c|}{ Age brackets } & $\begin{array}{l}\text { Points by the } \\
\text { MSHE }\end{array}$ & $\begin{array}{l}\text { Relevant (im- } \\
\text { pactful) points }\end{array}$ & $\begin{array}{l}\text { Irrelevant (lost) } \\
\text { points }\end{array}$ \\
\hline \multirow[t]{5}{*}{ Under 35} & Sum & 961.9 & 449.0 & 404.9 \\
\hline & Median & 90.464 & 37.750 & 34.048 \\
\hline & Mean & 96.186 & 44.900 & 40.486 \\
\hline & Std. Deviation & 60.1884 & 41.5878 & 24.2164 \\
\hline & $\mathrm{N}$ & 10 & 10 & 10 \\
\hline \multirow[t]{5}{*}{$36-40$} & Sum & 2075.6 & 845.5 & 1122.1 \\
\hline & Median & 113.750 & 50.000 & 60.833 \\
\hline & Mean & 129.723 & 52.844 & 70.129 \\
\hline & Std. Deviation & 79.3359 & 41.7851 & 46.6552 \\
\hline & $\mathrm{N}$ & 16 & 16 & 16 \\
\hline \multirow[t]{5}{*}{$41-45$} & Sum & 1423.3 & 490.5 & 848.8 \\
\hline & Median & 103.903 & 39.000 & 64.403 \\
\hline & Mean & 142.332 & 49.050 & 84.882 \\
\hline & Std. Deviation & 119.1626 & 46.2568 & 77.6320 \\
\hline & $\mathrm{N}$ & 10 & 10 & 10 \\
\hline \multirow[t]{5}{*}{$46-50$} & Sum & 804.6 & 248.0 & 508.6 \\
\hline & Median & 116.417 & 25.000 & 55.417 \\
\hline & Mean & 114.940 & 35.429 & 72.655 \\
\hline & Std. Deviation & 67.3189 & 37.1791 & 38.1132 \\
\hline & $\mathrm{N}$ & 7 & 7 & 7 \\
\hline \multirow[t]{5}{*}{$51-60$} & Sum & 859.5 & 358.7 & 500.8 \\
\hline & Median & 103.000 & 36.333 & 62.000 \\
\hline & Mean & 95.500 & 39.852 & 55.648 \\
\hline & Std. Deviation & 56.9649 & 34.2638 & 30.4543 \\
\hline & $\mathrm{N}$ & 9 & 9 & 9 \\
\hline
\end{tabular}




\begin{tabular}{|c|c|c|c|c|}
\hline \multicolumn{5}{|c|}{ Report } \\
\hline \multicolumn{2}{|c|}{ Age brackets } & $\begin{array}{c}\text { Points by the } \\
\text { MSHE }\end{array}$ & $\begin{array}{l}\text { Relevant (im- } \\
\text { pactful) points }\end{array}$ & $\begin{array}{l}\text { Irrelevant (lost) } \\
\text { points }\end{array}$ \\
\hline \multirow[t]{5}{*}{ Above 60} & Sum & 614.5 & 161.3 & 417.2 \\
\hline & Median & 66.000 & 13.000 & 31.000 \\
\hline & Mean & 68.279 & 17.926 & 46.353 \\
\hline & Std. Deviation & 45.4768 & 15.7892 & 46.5751 \\
\hline & $\mathrm{N}$ & 9 & 9 & 9 \\
\hline \multirow[t]{5}{*}{ Total } & Sum & 6739.3 & 2553.0 & 3802.3 \\
\hline & Median & 98.667 & 36.333 & 49.237 \\
\hline & Mean & 110.481 & 41.852 & 62.333 \\
\hline & Std. Deviation & 77.5468 & 38.4522 & 48.2933 \\
\hline & $\mathrm{N}$ & 61 & 61 & 61 \\
\hline
\end{tabular}

Source: Own analysis.

A more detailed breakdown of the variable "age" into a number of age brackets (Table 3 ) shows that the most productive age group in terms of relevant (impactful) points obtained are the employees in the 36-40 age range. They obtained the largest number of total points and relevant points for the FPSIS and had the highest median value for the latter of these parameters. It should be noted, however, that the number of irrelevant (lost) points was also the highest in this particular bracket. At the opposite end of the spectrum were the oldest scholars (over 60 years of age), with 614.5 points in total, out of which 161 were relevant (impactful) points. The medians for both parameters were 66 and 13, respectively, and were also the lowest recorded for all the brackets analyzed. Moreover, this oldest group is also the least internally varied in this respect (lowest value of standard deviation). However, the most interesting age group in the data set are the researchers aged between 46-50. The median for the number of total points obtained for this category was the highest of all (over 116), but in terms of parametrically impactful (relevant) points, the median value recorded was second to last ( 25 points). This is the biggest difference in median value position for the two variables among all the age brackets compared. This points to significant publishing potential that was not translated into impactful (relevant) points for the unit.

Calculation of the Spearman rank correlation coefficient (rs) to examine correlations between the employee age brackets listed in Table 3 (independent ordinal variable) and the number of points obtained (dependent ratio variable) did not confirm the correlations between these two variables. The results of the test performed were not statistically significant - statistical significance $(p>0.05)$ was recorded only 
with respect to employee performance in terms of relevant (impactful) points: $r s=$ -0.284 . This suggests a weak but nevertheless negative correlation between employee age (bracket) and the number of impactful (relevant) points obtained. Still, this conclusion backs up the arguments supporting our initial hypothesis.

H2. Gender is not correlated with the number of relevant (impactful) points obtained by an employee.

It turns out that in the studied population, contrary to expectations, gender is a differentiating factor in terms of the number of relevant (impactful) points obtained by an employee. As presented in Table 4, the women recorded higher median values by well over a dozen points, both for total points awarded and parametrically impactful (relevant) points. Analyzing the minimum and maximum point scores for both categories, however, it can be seen that the average number of points per publication is still higher for the women than the men. The women scored in the range of 45 to over 454 points (total points), 0 to 178.5 points (for impactful (relevant) points) and 13.8 to 264 for irrelevant (lost) points. For the men, these ranges were $13-237.5 ; 0-130.5$; and $0-168$, respectively.

Table 4. Analysis of correlation between gender of FPSIS employees and the number of relevant (impactful) points obtained for publications

\begin{tabular}{|c|c|c|c|c|}
\hline \multicolumn{5}{|c|}{ Report } \\
\hline & Gender & $\begin{array}{l}\text { Points by the } \\
\text { MSHE }\end{array}$ & $\begin{array}{l}\text { Relevant (im- } \\
\text { pactful) points }\end{array}$ & $\begin{array}{c}\text { Irrelevant (lost) } \\
\text { points }\end{array}$ \\
\hline \multirow[t]{5}{*}{ Women } & Sum & 2788.7 & $1,016.0$ & 1580.7 \\
\hline & Median & 111.000 & 38.000 & 51.667 \\
\hline & Mean & 132.795 & 48.381 & 75.271 \\
\hline & Std. Deviation & 102.5277 & 46.4155 & 59.2522 \\
\hline & $\mathrm{N}$ & 21 & 21 & 21 \\
\hline \multirow[t]{5}{*}{ Men } & Sum & 3950.6 & 1537.0 & 2221.6 \\
\hline & Median & 96.583 & 26.500 & 48.952 \\
\hline & Mean & 98.766 & 38.425 & 55.541 \\
\hline & Std. Deviation & 58.7533 & 33.6884 & 40.6225 \\
\hline & $\mathrm{N}$ & 40 & 40 & 40 \\
\hline \multirow[t]{5}{*}{ Total } & Sum & 6739.3 & 2553.0 & 3802.3 \\
\hline & Median & 98.667 & 36.333 & 49.237 \\
\hline & Mean & 110.481 & 41.852 & 62.333 \\
\hline & Std. Deviation & 77.5468 & 38.4522 & 48.2933 \\
\hline & $\mathrm{N}$ & 61 & 61 & 61 \\
\hline
\end{tabular}

Source: Own analysis. 
H3. Absence of family responsibilities in the form of a spouse (or steady partner) and minor children remaining directly under a researcher's care promotes a larger number of relevant (impactful) points obtained.

A very limited number (9) of employees who were not in steady relationships during the period under evaluation makes it impossible to make a fair comparison and verify the hypothesis that the lack of family commitments (marriage or cohabitation) is positively correlated with the number of impactful (relevant) points obtained (Table 5). If we consider the element of having minor children directly under one's care, then it turns out that both the number of total points obtained and the number of impactful (relevant) points obtained are higher among the employees taking care of children than among the childless. The median value difference is over 41 points in the total points and almost 17 for relevant points. The number of irrelevant (lost) points is also higher in that same category. This clearly demonstrates the fact that childcare does not constitute a barrier to frequent publication of one's scholarly work and, in the light of our data, even seems to be slightly beneficial for such activity.

Table 5. Analysis of correlation between family situation (dependent children under one's care) of FPSIS employees and the number of relevant (impactful) points obtained for publications

\begin{tabular}{|c|c|c|c|c|}
\hline \multicolumn{5}{|c|}{ Report } \\
\hline \multicolumn{2}{|c|}{$\begin{array}{l}\text { Dependent minor children under } \\
\text { their direct care? }\end{array}$} & $\begin{array}{l}\text { Points by the } \\
\text { MSHE }\end{array}$ & $\begin{array}{l}\text { Relevant (im- } \\
\text { pactful) points }\end{array}$ & $\begin{array}{l}\text { Irrelevant (lost) } \\
\text { points }\end{array}$ \\
\hline \multirow[t]{5}{*}{ No } & Sum & 3062.8 & 1283.2 & 1587.6 \\
\hline & Median & 70.000 & 26.000 & 45.000 \\
\hline & Mean & 98.800 & 41.392 & 51.214 \\
\hline & Std. Deviation & 70.1558 & 39.3895 & 35.7717 \\
\hline & $\mathrm{N}$ & 31 & 31 & 31 \\
\hline \multirow[t]{5}{*}{ Yes } & Sum & 3676.5 & 1269.8 & 2214.7 \\
\hline & Median & 111.833 & 39.000 & 57.542 \\
\hline & Mean & 122.551 & 42.328 & 73.823 \\
\hline & Std. Deviation & 83.9859 & 38.1264 & 56.8583 \\
\hline & $\mathrm{N}$ & 30 & 30 & 30 \\
\hline \multirow[t]{5}{*}{ Total } & Sum & 6739.3 & 2553.0 & 3802.3 \\
\hline & Median & 98.667 & 36.333 & 49.237 \\
\hline & Mean & 110.481 & 41.852 & 62.333 \\
\hline & Std. Deviation & 77.5468 & 38.4522 & 48.2933 \\
\hline & $\mathrm{N}$ & 61 & 61 & 61 \\
\hline
\end{tabular}

Source: Own analysis. 


\section{Conclusions}

The aim of the study was to determine the correlation (if such exists) between scientific productivity of researchers as expressed in publications and selected sociodemographic factors, such as age, gender and family situation. As the dataset analyzed was a small and unrepresentative sample in relation to the population of researchers in Poland, it cannot serve as a basis for any general conclusions. However, the authors see the study as an interesting pilot, a "prospective study" in an area previously not investigated. Firstly, the sociodemographic factors considered in the study are either entirely uncorrelated with scientific output and impact of work of a researcher, as measured by the number of points awarded by the MSHE in the process of the evaluation of scientific units once every four years, or correlated to a relatively small degree only. On the other hand, our research has shown that there is some connection between certain variables we were examining. First of all, gender turned out to be a differentiating factor in terms of point scores obtained (productivity). The women proved to be more productive in this respect than the men. We consider this to be an important and surprising finding, which of course requires confirmation in subsequent studies. In the case of the FPSIS employees, age was also significant. The scholars under 40 years of age obtained more impactful points for their publications than the older age bracket. It is worth noting that the results of our analyses, although carried out on a small population, are consistent with conclusions from other studies carried out worldwide. As concerns the new socio-demographic factor taken into account in our study, the results of the examination of the relation between family obligations and scholarly output and impactfulness were interesting as well. It was determined that the researcher's family situation impacts scientific productivity to a small degree only.

\section{References:}

Abramo, G., D’Angelo, C.A., \& Di Costa, F. (2011). Research productivity: Are higher academic ranks more productive than lower ones? Scientometrics, 88(3), 915-928. doi:10.1007/s11192-011-0426-6.

Abramo, G., D'Angelo, C.A., \& Murgia, G. (2015). The combined effects of age and seniority on research performance of full professors. Science and Public Policy, 43(3), 1-19. doi:10.1093/scipol/scv037.

Carayol, N., \& Matt, M. (2006). Individual and collective determinants of academic scientists' productivity. Information Economics and Policy, 18(1), 55-72. doi:10.1016/j. infoecopol.2005.09.002. 
Cole, S. (1979). Age and scientific performance. American Journal of Sociology, 84(4), 958-977. doi.org/10.1086/226868.

Costas, R., van Leeuwen, T.N., \& Bordons, M. (2010). A bibliometric classificatory approach for the study and assessment of research performance at the individual level: The effects of age on productivity and impact. Journal of the Association for Information Science and Technology, 61(8), 1564-1581. doi:10.1002/asi.21348.

Cronin, B., \& Meho, I. (2007). Timelines of creativity: A study of intellectual innovators in information science. Journal of the American Society for Information Science and Technology, 58(13), 1948-1959. doi:10.1002/asi.20667.

Jeran, A., Kącka, K., \& Piechowiak-Lamparska, J. (2017). Publication efficiency in science. suggestions on measures and their application using the case of Poland and Nicolaus Copernicus University in Torun. The New Educational Review, 49(3), 138-153. doi:10.15804/tner.2017.49.3.11.

Kelchtermans, S., \& Veugelers, R. (2013). Top research productivity and its persistence: Gender as a double-edged sword. Review of Economics and Statistics, 95(1), 273-285. doi:10.1162/REST_a_00275.

Kretschmer, H., \& Kretschmer, T. (2013). Gender bias and explanation models for the phenomenon of women's discriminations in research careers. Scientometrics, 97(1), 25-36. doi:10.1007/s11192-013-1023-7.

Noordenbos, G. (1992). Explanations for differences in publication rates between male and female academics and between productive and less productive women. Bulletin of Sociological Methodology/Bulletin de Méthodologie Sociologique, 35(1), 22-45. doi:10.1177/075910639203500102.

Puuska, H.M. (2010). Effects of scholar's gender and professional position on publishing productivity in different publication types. Analysis of a Finnish university. Scientometrics, 82(2), 419-437. doi:10.1007/s11192-009-0037-7.

Rørstad, K., \& Aksnes, D.W. (2015). Publication rate expressed by age, gender and academic position - A large-scale analysis of Norwegian academic staff. Journal of Informetrics, 9(2), 317-333. doi:10.1016/j.joi.2015.02.003.

Rozporządzenie Ministra Nauki i Szkolnictwa Wyższego z dnia 12 grudnia 2016 r. w sprawie przyznawania kategorii naukowej jednostkom naukowym i uczelniom, w których zgodnie $\mathrm{z}$ ich statutami nie wyodrębniono podstawowych jednostek organizacyjnych. Dziennik Ustaw, poz. 2154 [Regulation of the Minister of Science and Higher Education of 12 December 2016 on granting of scientific ranks to scientific units and universities in which, pursuant to their statutes, core organizational units have not been delimited, Journal of Laws, item 2154]. 